\title{
PERCEPÇÃO DE PUÉRPERAS SOBRE A EDUCAÇÃO EM SAÚDE COMO DISPOSITIVO DE INCENTIVO AO PARTO NORMAL
}

\author{
MOTHERS' PERCEPTION OF THE HEALTH EDUCATION AS \\ AN INCENTIVE DEVICE TO NORMAL DELIVERY
}

\section{Leyna Jordânia Alves da Costa', Mauriza da Silva Lima', Fabyanna dos Santos Negreiros', Jardeliny Corrêa da Penha², Anne Karollyne de Freitas Bonfim Figueiredo ${ }^{3}$, Antônia Sylca de Jesus Sousa²}

\begin{abstract}
RESUMO
Objetivo: Analisar a percepção de puérperas sobre ações educativas desenvolvidas durante o prénatal para o incentivo ao parto normal. Metodologia: Estudo exploratório-descritivo, de abordagem qualitativa, realizado com 14 puérperas cadastradas numa unidade básica de saúde do município de Floriano-PI. A coleta de dados ocorreu em novembro de 2015, por meio de entrevista semiestruturada. Os dados foram analisados pela técnica de conteúdo categorial temática. A pesquisa foi aprovada pelo Comitê de Ética em Pesquisa da Universidade Federal do Piauí. Resultados: Das 14 entrevistadas, seis participaram de atividades educativas durante o pré-natal, sendo o enfermeiro o profissional mais citado na realização das mesmas. Ademais, as mesmas consideraram ser importante a realização de tais ações, tendo em vista os anseios e dúvidas sobre o parto. Considerações finais: A preparação para o parto normal por meio de ações educativas proporciona confiança à gestante, sendo necessária a capacitação permanente dos profissionais envolvidos, especialmente do enfermeiro.
\end{abstract}

Descritores: Cuidado Pré-Natal; Educação em Saúde; Parto Normal.

\begin{abstract}
Objective: To analyze the perception of mothers on educational activities developed during the prenatal care for encouraging normal delivery. Methodology: A descriptive exploratory study of qualitative approach, conducted with 14 mothers enrolled in a basic health unit in the city of Floriano-PI. Data collection took place in November 2015, through semi-structured interview. Data were analyzed by the content of technical thematic category. The study was approved by the Ethics Committee of the Federal University of Piauí. Results: Of the 14 interviewed, six participated in educational activities during prenatal care, and nurses the most cited professional in meeting them. Moreover, they considered it important to carry out such actions, in view of the concerns and doubts about the delivery. Final remarks: The preparation for the normal delivery through educational activities provides confidence to pregnant women, requiring the permanent training of the professionals involved, especially nurses.
\end{abstract}

Descriptors: Prenatal Care; Health Education; Natural Childbirth.
${ }^{1}$ Formada em Enfermagem pela Universidade Federal do Piauí (UFPI), Floriano, PI, Brasil.

${ }^{2}$ Mestre em Cuidados Clínicos em Enfermagem e Saúde pela Universidade Estadual do Ceará (UECE), Fortaleza, CE, Brasil.
${ }^{3}$ Especialista em Urgência e Emergência pela Unidades Integradas de Pós-graduação, Pesquisa e Extensão (UNIPÓS), Teresina, PI, Brasil. 


\section{Introdução}

Mais de quarenta anos atrás, a maioria dos partos ocorria, em maioria, por via vaginal (partos normais), alguns em domicílios, com auxílio de parteiras ${ }^{1}$. No entanto, desde a década de 90 , o Brasil vivencia uma mudança no padrão de nascimento, em que a operação cesariana tornou-se a via de nascimento mais comum. Esta última, quando realizada sob indicações médicas específicas, constitui uma cirurgia essencial para a saúde materna e infantil, mas, se realizada sem indicação médica adequada e justificável, pode levar ao aumento do risco de complicações graves².

Sabe-se que entre as causas do elevado índice de cesáreas estáa insegurança da mulher, ocasionada pela sua desinformação em relação ao parto normal e insatisfação com a falta de oportunidade para expressar suas expectativas e preocupações ${ }^{3}$. Ademais, citam-se os mitos e tabus construídos sobre a gestação e os tipos de parto, a atenção à saúde que ainda tende a privilegiar apenas os aspectos biológicos e as condições dos serviços oferecidos à população assistida que deixam a desejar.

Com base nisso, em 2000, o Ministério da Saúde (MS), instituiu o Programa de Humanização no Pré-natal e Nascimento ${ }^{5}$. Em 2006, realizou a Campanha Nacional de Incentivo ao Parto Normal e Redução da Cesárea Desnecessária e lançou, em 2008, a Política Nacional pelo Parto Natural e Contra as Cesáreas Desnecessárias, em parceria com a Agência Nacional de Saúde Suplementar (ANS) ${ }^{6}$. Além destas, outras estratégias foram desenvolvidas, como o Programa Rede Cegonha, instituído em 2011 e que objetiva ampliar o acesso e a melhoria da qualidade da atenção pré-natal, da assistência ao parto e puerpério e da assistência à criança até 24 meses de vida ${ }^{7}$.

Os objetivos da Rede Cegonha partem ainda da proposta de humanização do parto. Em consideração a isto, é importante destacar que os profissionais que acompanham o pré-natal, em especial os enfermeiros, possuem papel fundamental no cuidado humanizado e de qualidade à gestante, permitindo que as mudanças e o empoderamento desta, efetivamente ocorram. Para tal, é necessário agregar ao cuidado ações educativas visando um parto saudável, desconstruindo mitos que interferem neste momento ${ }^{8}$.

O pré-natal é o período da gravidez mais adequado para o desenvolvimento de ações educativas, tanto nos espaços de atendimento individual, quanto nos processos em grupos para a promoção do parto normal ${ }^{9}$. Tais ações educativas dizem respeito às atividades de educação em saúde, voltadas para o desenvolvimento de capacidades individuais e coletivas, que visa a melhoria da qualidade de vida e saúde do binômio mãe-filho, bem como uma gestação e nascimento saudáveis ${ }^{10}$.

Em estudo, que objetivou conhecer os significados e a contribuição de um Grupo de Gestantes e Casais Grávidos, verificou-se, segundo as gestantes e acompanhantes, que compartilhar conhecimentos e vivências por meio de grupos de educação em saúde sobre o processo de nascimento fortaleceu seus potenciais, reduziu medos e deu tranquilidade para seguir o ritmo e os sinais emitidos pelo corpo da gestante, aumentou a sua confiança para fazer escolhas sobre as vantagens e desvantagens dos vários tipos de parto, assim como conhecer as técnicas não farmacológicas para minimizar as sensações dolorosas. Ademais, deu mais segurança e esclareceu dúvidas para decidir qual a hora de ir para maternidade e condutas para cuidar de si e do filho ${ }^{11}$.

Em face do exposto, há que se mencionar que o enfermeiro é responsável pela educação em saúde durante a assistência pré-natal que realiza, ocorrendo, assim, um processo de ensinar e aprender que pode proporcionar uma construção compartilhada de conhecimentos entre a gestante e profissional, e esses conhecimentos podem transformar a vida de uma pessoa quando esta assume a capacidade de tomar suas próprias decisões de forma consciente e responsável, de modo a promover a preparação da gestante para o parto, proporcionando-lhe confiança em ter um parto normal. Diante do exposto, o presente estudo objetivou analisar a percepção de puérperas sobre ações educativas desenvolvidas durante o pré-natal para o incentivo ao parto normal.

\section{Metodologia}

Tratou-se de um estudo exploratório-descritivo, de abordagem qualitativa, realizado em uma Unidade Básica de Saúde (UBS), localizada na zona urbana do município de Floriano-PI. Esta UBS foi selecionada por ter maior número de puérperas cadastradas.

Os sujeitos do estudo foram puérperas atendidas em uma UBS do município citado. Escolheram-se puérperas pelo fato das mesmas terem vivenciado o período gestacional e por supor que elas tiveram a oportunidade de participar de ações educativas durante o pré-natal. 
Foram selecionadas as puérperas que atenderam aos seguintes critérios de inclusão: ter idade igual ou superior a 18 anos; que realizaram o acompanhamento pré-natal na UBS selecionada, tendo participado de pelo menos seis consultas pré-natais. Foram critérios de exclusão: apresentar transtorno mental ou alguma deficiência que a impossibilitasse de responder os questionamentos. Destarte, ressalta-se que participaram da pesquisa 14 puérperas .

O total de sujeitos foi obtido a partir da técnica de saturação teórica, ou seja, suspendeu-se a inclusão de novas participantes quando a pesquisadora principal percebeu que os dados obtidos apresentavam redundância ou repetição. A saturação teórica foi constatada na décima entrevista, através da repetição das informações fornecidas pelos sujeitos do estudo, apesar disso, optou-se por entrevistar mais quatro participantes, comprovando-se assim de forma mais fidedigna o método de saturação.

Para a preservação da identidade das participantes, as mesmas foram identificadas por meio da letra "P", seguida de numeral arábico, que indica a ordem em que as entrevistas aconteceram.

A coleta de dados aconteceu em novembro de 2015, por meio de entrevista individual e semiestruturada. Os dados foram coletados apenas pela pesquisadora principal, a qual utilizou um gravador de voz para armazenamento das falas e um roteiro com perguntas norteadoras referentes à caracterização sociodemográfica e obstétrica das puérperas, bem como sobre a percepção das mesmas acerca da educação em saúde como dispositivo de incentivo ao parto normal.

Os dados coletados foram analisados pelo método de conteúdo categorial temática, baseada nas propostas apresentadas por Bardin (2011). Destarte, análise seguiu as seguintes etapas: momento I- pré-análise, organização do material investigado; momento II- exploração do material, construção das operações de codificação, considerando-se os recortes dos textos em unidades de registros ou temas e a classificação e agregação das informações em categorias temáticas; e momento III- tratamento dos resultados obtidos e interpretação ${ }^{12}$.

Destaca-se ainda que os aspectos éticos de pesquisas envolvendo seres humanos foram respeitados, sendo que foi lido pela pesquisadora e solicitada a assinatura ou impressão digital, por meio do polegar, em duas vias, às participantes o Termo de Consentimento Livre e Esclarecido (TCLE). O estudo aprovado pelo Comitê de Ética da Universidade Federal do Piauí, Campus Amílcar Ferreira Sobral da Universidade Federal do Piauí, por meio do parecer 1.385.028.

\section{Resultados e Discussão}

Foram entrevistadas 14 puérperas e a respeito da caracterização sociodemográfica das mesmas, identificou-se que cinco delas $(35,7 \%)$ possuíam ensino médio completo; sete $(50,0 \%)$ eram casadas; e quatro $(57,2 \%)$ tinham uma renda mensal de um salário mínimo. Em relação aos dados obstétricos, ainda sobre as 14 participantes, nove $(35,7 \%)$ dessas tinham tido duas ou mais gestações; outras nove $(35,7 \%)$, dois ou três filhos; oito $(57,2 \%)$ tiveram parto cesáreo nas gestações anteriores; e, acerca do último pré-natal, sete $(50,0 \%)$ participaram de sete consultas, realizadas pelo enfermeiro ou pelo médico da equipe.

Abaixo são apresentadas as categorias temáticas, são elas: participação das mulheres em atividades educativas e a importância dessas ações durante o pré-natal; e educação em saúde: dispositivo para incentivo ao parto normal.

\section{Participação das mulheres em atividades educativas e a importância dessas ações durante o pré-natal}

Das 14 puérperas entrevistadas, apenas seis (42,9\%) participaram de atividades educativas durante o pré-natal. Entre os fatores que dificultaram a participação das demais mulheres nas ações educativas destacam-se: a não realização e/ou divulgação dessas ações, o fato da mulher trabalhar e não ser liberada, a falta de tempo para participar e ainda por não ter com quem deixar os filhos; como pode ser observado nos discursos abaixo:

(...) não houve essas ações no meu posto e se houve não foram informadas nem por enfermeira nem pela agente de saúde, não houve informações a respeito. (P1)

Não teve nenhuma, não fui comunicada. (P2)

A questão do tempo porque eu também trabalho. (P6)

Porque eu não posso sair daqui por causa dos meninos e eu não tenho com quem deixar. (P12) 
A falta de tempo mencionada por uma das puérperas também foi citada em outro estudo como um dos fatores que poderiam impedir a participação das mulheres em ações educativas ${ }^{13}$. Cabe ressaltar que na maioria das vezes a mulher possui um emprego formal e, além disso, são responsáveis pelos afazeres domésticos e cuidados com os filhos.

Quando questionadas a respeito do profissional que conduzia as ações educativas, das seis puérperas que participaram de ações educativas, quatro $(04,66,6 \%)$ afirmaram que eram realizadas somente pelo enfermeiro. Nota-se que o enfermeiro foi o profissional mais citado quanto ao desenvolvimento das atividades educativas. Esses resultados são de certa forma esperados, tendo em vista que a assistência à mulher no período gravídico-puerperal constitui-se uma tradicional vertente da atuação profissional do enfermeiro.

A atuação do enfermeiro nas práticas educativas é muito importante, pois é notório que o mesmo tem se tornado indispensável na promoção de tais atividades. A educação em saúde faz parte da rotina diária deste profissional, especialmente quando o assunto é pré-natal, por isso, é necessário que este compreenda a importância de humanizar e qualificar a atenção prestada às gestantes para garantir melhor adesão e início precoce ao pré-natal ${ }^{14}$.

Sobre a importância da realização de ações educativas durante o pré-natal para incentivar o parto normal, as participantes do estudo mencionaram ser fundamental a participação em ações educativas com o objetivo de saber as vantagens deste tipo de parto e de como se preparar para o momento do trabalho de parto.

Eu considero importante porque é necessário educação para que as pessoas possam conhecer, né? Os benefícios do parto normal e muitas pessoas não têm informações a respeito disso, né? Outras têm, mas não optam por medo, por tabu, por achar que não é importante e não traz benefícios para a saúde da mãe e da criança. (P1)

Ademais, o tabu pode influenciar diretamente a percepção da mulher sobre a gestação e o parto. As mulheres optam pelo parto cesáreo por medo da dor que podem sofrer com o parto normal e por relatos de experiências negativas de outras mulheres. Visto que o contexto sociocultural no qual a mulher está inserida subsidia diretamente a construção de suas percepções sobre o parto ${ }^{15}$.

O medo citado pela entrevistada nem sempre estará relacionado à dor, mas ao receio da própria morte ou da morte do bebê durante o trabalho de parto ${ }^{16}$. Com isso, elevam-se a ansiedade, o nervosismo e o desespero que resultam numa experiência, muitas vezes, traumática.

Nesse sentido o pré-natal e mais especificamente o trabalho educativo realizado nos serviços de saúde, apresentam-se como dispositivos oportunos e adequados à construção e partilha do conhecimento entre gestantes e profissionais de saúde, buscando integrar esse conhecimento em benefício e incentivo ao parto normal ${ }^{9}$.

\section{Educação em saúde: dispositivo para incentivo ao parto normal}

A educação em saúde desenvolvida durante o pré-natal pode promover um aprendizado prático que contribui para tornar as mulheres mais preparadas para lidar com o momento do parto, especialmente o parto normal, assim como também com os acontecimentos e situações que se relacionam com sua saúde, conforme ilustrado nos relatos a seguir:

(...) a pessoa com conhecimento quando ela sentir as contrações ela num vai se desesperar na hora porque ela já teve uma orientação antes então ela vai ficar mais tranquila e aí vai ter um parto bem ligeiro como a mim que foi só sete minutos. (P5)

Acho bastante importante porque a gente tendo informação é até mais fácil da gente se ajudar lá, que na hora lá são muitas mulher pra ter menino e a enfermeira não sabe quem olha, por isso é importante a gente sabendo o que fazer pra poder reagir e ajudar. (P10)

E ao serem questionadas sobre terem recebido orientações acerca do parto normal durante o pré-natal, algumas puérperas responderam afirmativamente, como se revela nos seguintes depoimentos:

Ela falou do parto normal, a questão da recuperação, da amamentação também que era importante e dicas mesmo de como eu posso eu me comportar no parto. (P4) 
Ele me falava o jeito que era melhor pro bebê nascer mais rápido, quando sentir as contrações o que eu faria, que era respirar fundo depois soltar. (P5)

Eles disseram pra eu ficar de repouso, relaxando, fazendo exercício físico. (P9)

Ela explicava que era melhor eu ter o parto normal porque ajudava mais na recuperação. (P10)

As respostas das mulheres quanto às informações recebidas sobre o parto normal sugerem explicações vagas e pouco consistentes. Os aspectos relacionados especificamente às contrações uterinas e à recuperação, em detrimento dos demais aspectos relacionados ao parto, configuram insuficiência de informações, apesar dos enfermeiros reconhecerem a importância de atividades de educação em saúde dirigidas às gestantes no transcorrer das consultas de enfermagem durante o pré-natal ${ }^{17}$.

A segurança da mulher durante o trabalho de parto dependerá do preparo para esse evento ao longo da gravidez, destacando o papel do profissional que acompanha o pré-natal e realiza ações educativas ${ }^{18}$. Entretanto, como se observa nos depoimentos abaixo, esse preparo nem sempre é possível, pois as mesmas não têm a assistência daquele profissional para auxílio no momento de transição entre a gestação e o parto:

A hora que a gente tem mais dúvida é a hora que a gente vai ter uma criança, então nessas horas a gente quer uma opinião de um profissional, tá mais presente da gente, o que a gente deve fazer, como agir e ás vezes a gente não tem essa presença de um profissional. (P2)

Seria melhor que tivesse profissionais melhor porque não tem. Você chega lá e faz só a consulta de pré-natal e só isso, só o que pede mesmo no cartão da gestante. (P11)

Quando indagadas sobre o tipo de parto que desejavam ter, percebeu-se que esta decisão desperta muitos sentimentos e opiniões. Portanto, os discursos abaixo são referentes ao tipo de parto desejado por elas e as principais justificativas no que diz respeito a essa decisão:

Normal. Porque o normal ele, além de ser rápido e não tem aquele resguardo todo, a recuperação, eu com cinco dias eu já tava normal, já o cesáreo não, o cesáreo tem mais dificuldade, já é mais rígido (...). (P2)

Normal, com certeza normal porque evita uma cirurgia que é o que todo mundo tem medo e é bem melhor, a recuperação é sem comparação, logo, logo a pessoa se recupera e evita complicações. (P13)

Eu queria normal porque eu morava sozinha, minha mãe não morava aqui e tudo era eu pra fazer as coisas, aí não tinha ninguém pra me ajudar. (P10)

Normal. Pelo fato de ser mais natural e também de não ter que ficar três meses dependendo de todo mundo e porque é melhor pro bebê também. (P11)

Percebe-se que as puérperas fazem comparações entre os tipos de parto, normal e cesáreo quando em algumas de suas falas elas tentam expressar os perigos de uma cesariana como possíveis complicações cirúrgicas. Sobre as percepções negativas do parto cesáreo, foram mencionados o medo da cirurgia, as dificuldades na recuperação, complicações e maior dependência para a realização das atividades diárias.

Decerto a preferência pelo parto normal, que ocorre na grande maioria das mulheres, é justificada pelo fato de que o mesmo possibilita a cicatrização, a amamentação e recuperação mais rápida, não interferindo na rotina e autonomia, além das inconveniências causadas pela cesariana, quais sejam as dores e desconfortos que ocorrem geralmente após o nascimento da criança ${ }^{8}$.

Entende-se que são inúmeros os benefícios do parto normal tanto para a mãe quanto para o bebê, os quais vão desde uma melhor e rápida recuperação da mulher e menor risco de aquisição de infecção hospitalar, até uma incidência menor de desconforto respiratório para o bebê. Sendo assim, o parto normal proporciona a mãe uma recuperação pósparto praticamente imediata, podendo a mesma voltar aos seus afazeres bem mais precocemente, sem a influência da anestesia e sem as dores da incisão cirúrgica, feita na cesariana ${ }^{19}$. 
As mulheres que tiveram preferência pela operação cesariana justificaram tal escolha pela falta de confiança no profissional, insegurança, pois não poderiam realizar o parto com o mesmo médico que as acompanhavam durante 0 pré-natal e pelas condições precárias de assistência ao parto normal oferecida pela Rede Básica de Saúde, consoante pode ser observado por meio dos seguintes depoimentos:

Eu desejava ter um parto normal, mas eu encontrei muitas dificuldades (...). Na rede básica de saúde, a insegurança por você não fazer um parto com o mesmo médico que te acompanha. (...), não é uma coisa que te dá segurança né? aí quando você opta pela rede particular essa situação piora mais ainda. Não tem médico disponível, o médico você tem que marcar data e a gente não tem como prever qual o dia do parto normal né? (...) a rede básica de saúde, que é muito precária, então quando você opta pela rede particular você não tem nem como fazer porque o médico diz que não tem como te dar assistência dependendo do dia, dependendo da hora, então, traz muita insegurança. (...) eu comecei a ter alguns sinais, pequenos sangramentos, então eu fiquei muito nervosa e optei pela cesariana (expressão de tristeza). (P1)

Eu desejava ter normal. Eu não tive normal, assim, não culpo a médica, mas ela num passou a confiança que eu necessitava de me acompanhar durante aquele processo do parto normal, ou seja, como é que posso dizer? Ela não tinha aquela disponibilidade, aí eu me senti obrigada a fazer o parto cesariano mesmo porque eu não ia ter 0 acompanhamento dela, porque o parto normal ele requer né? Dum profissional, que ele esteja ali disponível e ela não tinha essa disponibilidade. (P4)

Percebe-se pelas falas que, embora essas mulheres preferissem o parto normal, elas aderiram ao parto cesáreo em decorrência da insuficiência de informações sobre aspectos que envolvem o trabalho de parto, como também a insuficiência de profissionais para prestar a assistência ao parto normal.

Esses fatores devem-se a maneira como a assistência ao nascimento é organizada em nosso país, ainda bastante centralizada na atuação de obstetras individuais em contraposição à abordagem multidisciplinar e de equipe, a qualidade dos serviços que deixa a desejar em sua capacidade de acolher a mulher e as características da assistência pré-natal, que comumente deixa de preparar as mulheres para o parto de forma adequada ${ }^{2}$.

Diante desse contexto, o MS tem proposto o resgate do parto normal, com estímulo da atuação da enfermeira obstetra na assistência à gestação e parto, a fim de respeitar e criar condições para que todas as dimensões espirituais, psicológicas e biológicas do ser humano sejam atendidas ${ }^{20}$. Muitos estudos apontam ser a enfermeira obstetra um dos profissionais mais apropriados para o acompanhamento da gestação e partos normais de baixo risco e evidenciam que os partos assistidos por elas apresentam menores índices de cesarianas e intervenções desnecessárias ${ }^{21}$.

Outras justificativas para a escolha da cesariana apresentadas foram atribuídas às experiências anteriores não exitosas de outras mulheres com o parto normal, os partos anteriores terem sido cesáreo e o desejo em realizar a laqueadura tubária intraparto com método contraceptivo definitivo. Conforme se observa nos recortes abaixo:

Cesáreo mesmo porque eu já vi muitos casos de pessoas ter perdido seus filhos por causa de algumas falhas de alguns profissionais da área da saúde e eu achava que tendo cesáreo com o acompanhamento do médico ele poderia ter um acompanhamento melhor comigo. (P6)

Eu queria normal, mas os meus todos os dois foi cesáreo, eu não pude ter normal, mas desejava normal porque a recuperação é bem melhor. (P8)

Eu tive os três (partos) normal, mas esse último eu queria cesáreo pra ligar. (P10)

Pelos relatos acima, percebe-se que a escolha pela cesariana entre as gestantes muitas vezes não é baseada em esclarecimentos corretos. Além do mais, dentre as seis que participaram de atividades educativas, apenas duas tiveram parto normal. Daí a importância de ser realizada uma assistência pré-natal adequada, com o desenvolvimento de ações educativas que apresentem informações precisas e que auxiliem as gestantes a compreenderem melhor os riscos e os benefícios, os mitos e as crendices relacionados ao tipo de parto. 
Embora os tipos de parto não devam ser vistos como uma simples questão de preferência, conforme preconiza o MS, é necessário que essas mulheres façam uma escolha antecipada sobre este de acordo com informações e esclarecimentos corretos adquiridos a partir dos profissionais que as acompanham no pré-natal, com ênfase nos riscos e benefícios implicados em cada um deles para que elas possam reivindicar aquilo que é melhor para a sua saúde e de seu filho22.

Nesse sentido o trabalho educativo com as mulheres deve ser realizado com a abrangência na produção de informações garantidas às gestantes desde 0 início da gestação, durante 0 acompanhamento pré-natal, criando oportunidade de envolvimento da mulher e de seus familiares, na promoção do parto normall ${ }^{7}$. A consulta à gestante pode ser usada como uma ferramenta propícia ao acolhimento e vínculo na rede de serviços de saúde, e como um momento privilegiado de preparo da gestante para o parto normal, podendo se constituir como um veículo legítimo de informações sob os aspectos técnicos e tecnológicos do parto, as repercussões positivas à sua saúde e à saúde do bebê.

\section{Considerações Finais}

Foi possivel perceber, neste estudo, que as puérperas compreendem o processo de educação em saúde e atribui a este, relevância significativa para o aprendizado dos fatores que envolvem a gestação e o parto normal. No entanto, evidenciou-se que a maioria das puérperas relatou não ter participado de ações educativas sobre o parto normal durante o pré-natal; porém, ressalta-se que a prática de tais atividades não constituía, conforme relatos, uma atividade rotineira e permanente na UBS em que o estudo foi realizado.

Ademais, quando as ações educativas aconteciam, as mesmas baseavam-se apenas na transmissão, de forma superficial e em momentos únicos e pontuais da consulta pré-natal, sobre amamentação, alimentação, parto normal, a importância do pré-natal, os cuidados com o bebê logo ao nascer e as vacinas que deve receber.

Diante disso, faz-se necessário a capacitação permanente dos profissionais envolvidos no pré-natal, em especial do enfermeiro, como forma de incentivar o desenvolvimento de ações educativas durante o período gestacional, que possam promover a saúde e o empoderamento das mulheres grávidas, bem como a construção do conhecimento coletivo. Isto permitirá que elas conheçam todos os aspectos que envolvem a gestação e o momento do parto, visto que a preparação para o parto por meio de ações educativas proporciona confiança à gestante em ter um parto normal, à medida que ameniza o medo e a tensão, e desperta para a mudança de concepções e de práticas.

\section{Referências}

1. Martins-Costa S, Ramos JGL. A questão das cesarianas. Rev Bras Ginecol Obstet. 2005; 27(10):571-574.

2. Ministério da Saúde (BR). Secretaria de Ciência, Tecnologia e Insumos Estratégicos. Diretrizes de Atenção à Gestante: a Operação Cesariana. Brasília: Ministério da Saúde, 2015.

3. Lamy GO, Moreno BS. Assistência pré-natal e preparo para o parto. Omnia Saúde. 2013; 10(2):19-35.

4. Morais FRR, Nunes TP, Veras RM, Azevedo LFM. Conhecimentos e expectativas de adolescentes nuligestas acerca do parto. Psicologia em Estudo. 2012; 17(2):287-295.

5. Brasil. Ministério da Saúde. Portaria $n^{0} 569$, de $1^{0}$ de junho de 2000. Institui o Programa de Humanização no Pré-natal e Nascimento, no âmbito do Sistema Único de Saúde. Diário Oficial da União, Brasília, 8 jun. 2000. Seção 1, p. 4, 5 e 6. 6. Mendonça SS. Mudando a forma de nascer: agência e construções de verdades entre ativistas pela humanização do parto [dissertação], 2013.

7. Cavalcanti PCS. O modelo lógico da rede cegonha [monografia]. Recife (PE): Residência Multiprofissional em Saúde Coletiva, Departamento de Saúde Coletiva, Centro de Pesquisas Aggeu Magalhães, Fundação Oswaldo Cruz; 2010.

8. Silva SPC, Prates RCG, Campelo BQA. Parto normal ou cesariana? fatores que influenciam na escolha da gestante. RevEnferm UFSM. 2014; 4(1):1-9.

9.Costa AP, Bustorff LACV, Cunha ARR, Soares MC.S, Araújo VS. Contribuições do pré-natal para o parto vaginal: percepção de puérperas. Rev. Rene. 2011; 12(3):548-54.

10. Souza VB, Roecker S, Marcon SS. Ações educativas durante a assistência pré-natal: percepção de gestantes atendidas na rede básica de Maringá-PR.Rev. Eletr. Enf. 2011;13(2):199-210.

11. Zampieri MFM, Gregório VRP, Custódio ZAO, Regis MI, Brasil C. Processo educativo com gestantes e casais grávidos: possibilidade para transformação e reflexão da realidade. Texto Contexto Enferm. 2010;19(4):719-27. 
12. Bardin L. Análise de conteúdo. 70.ed.Lisboa; 2011.

13. Santos AL, Radovanovic CAT, Marcon SS. Assistência pré-natal: satisfação e expectativas. Rev. Rene. 2010; 11(Número Especial):61-71.

14. BarbosaTLA, Gomes, L.M.X, Dias, O.V. O pré-natal realizado pelo enfermeiro: a satisfação das gestantes. CogitareEnferm. 2011; 16(1):29-35.

15. Campos AS, Almeida ACCH, Santos RP. Crenças, mitos e tabus de gestantes acerca do parto normal. Rev. Enferm. UFSM. 2014; 4(2): 332-341.

16. Rodrigues AV, Siqueira AAF. Sobre as dores e temores do parto: dimensões de uma escuta. Revista Brasileira de saúde materno-infantil. 2008; 8(2):179-186.

17. Moura ERF, Rodrigues MSP. Comunicação e informação em Saúde no pré-natal. Interface Comun, Saúde, Educ. 2003; 13(7):109-18

18. Silvestre DR, Pereira AKAM, Nascimento EGC, Júnior JMP. Via de parto orientada no pré-natal e a escolha da enfermeira no seu próprio parto. Rev. enferm. UFPE online. 2014; 12(8):4230-6.

19. Ministério da Saúde (BR). Pré-natal e Puerpério: atenção qualificada e humanizada - manual técnico. Secretaria de Atenção à Saúde, Departamento de Ações Programáticas Estratégicas. Brasília: Ministério da Saúde, 2005.

20. Castro JC, Clapis MJ. Parto humanizado na percepção das enfermeiras obstétricas envolvidas com a assistência ao parto. Rev. Latino-Am. Enfermagem. 2005; 13(6): 960-7.

21. Merighi MAB, Gualda DMR. Anatomia de uma conciliação: a enfermeira obstetra e as tendências de assistência à mulher. RevDiagn Tratamento. 2002; 7(2):6-10.

22. Ministério da Saúde (BR). Parto, aborto e puerpério: assistência humanizada à mulher. Secretaria de Políticas de Saúde, Área Técnica da Mulher. Brasília: Ministério da Saúde, 2001.

\section{Jardeliny Corrêa da Penha}

Endereço para correspondência - Rua: Coelho Rodrigues, $n^{\circ}$ : 350, Bairro: Ibiapaba,

CEP: 64803-035, Floriano, PI, Brasil.

E-mail: jardelinypenha@yahoo.com.br

Lattes: http://lattes.cnpq.br/4176449635531761

Leyna Jordânia Alves da Costa - leynajordania@hotmail.com

Mauriza da Silva Lima - mauriza_kiss@yahoo.com.br

Fabyanna dos Santos Negreiros - fabyannanegreiros7@hotmail.com

Anne Karollyne de Freitas Bonfim Figueiredo - karolbonfimfigueiredo@hotmail.com

Antônia Sylca de Jesus Sousa - sylcasousa88@hotmail.com

\section{Enviado em 20 de setembro de 2016. Aceito em 28 de julho de 2017.}

